This report was prepared as an account of work sponsored by an agency of the United States Government. Neither the United States Government nor any agency thereof, nor any of their employees, makes any warranty, express or implied, or assumes any legal liability or responsibility for the accuracy, completeness, or usefulness of any information, apparatus, product, or process disclosed, or repiesents that its use would not infringe privately owned rights. Reference herein to any specific commercial product, process, or service by trade name, trademark, manufacturer, or otherwise does not necessarily constitute or imply its endorsement, recommendation, or favoring by the United States Government or any agency thereof. The views and opinions of authors expressed herein do not necessarily state or reflect those of the United States Government or any agency thereof.

\section{THE DEGRADATION OF ORGANIC DYES BY CORONA DISCHARGE}
S. C. Goheen
M. McCulloch
D. E. Durham
W. 0 . Heath

DE92 010865

$$
\text { APR O } 1992
$$

February 1992

Presented at the

Chemical Oxidation: Technology for the 90's Conference

February 19-21, 1992

Nashville, Tennessee

Work supported by

the U.S. Department of Energy

under Contract DE-ACO6-76RLO 1830

Pacific Northwest Laboratory

Richland, Washington 99352 


\section{ABSTRACT}

Several dyes in water were individually exposed to corona discharge. Light absorbance decreased for all organic dyes with time. Absorbance losses with methylene blue, malachite green, and new coccine were studied. The loss of color was followed using an in situ colorimeter and the effects of varying the current, voltage, gas phase, stirring rates, salinity, and electrode spacing were investigated. The highest reaction rates were observed using the highest current, highest voltage (up to $10 \mathrm{kV}$ ), highest stirring rate, lowest salinity, smallest electrode spacing, and an environment containing enhanced levels of oxygen. Current was higher in the presence of nitrogen than in the presence of oxygen (for the same voltage), but the reaction of methylene blue did not proceed unless oxygen was present. These results help identify conditions using corona discharge in which dyes, and potentially other organics, can be destroyed.

\section{BACKGROUND}

Relatively little research has focused on the destructive capabilities of corona discharge for organic or biochemicals. polychlorinated biphenyls (PCBs) and other halogenated organics may be easily broken down into a mixture of harmless chemicals using superoxide $\left(\mathrm{O}_{2}^{-}\right)$generated in solution [1].

The oxidizing environment caused by corona discharge is believed to be potent, generating electrons, negative molecular ions (including ions of nitrogen and oxygen), ozone and ultraviolet light [2]. Corona discharge has been reported to destroy aerosolized bacterial spores of Bacillus thermophillius, reducing the spore concentration >99\% [2]. These authors further proposed that corona discharge might also fragment both harmful bacterial spores and toxic organic

Steve C. Goheen, Pacific Northwest Laboratories, P. O. Box 999, Richland, WA 99352 
materials. Two articles have reported the oxidation of biomolecules in the laboratory using corona discharge. One of these reported the oxidation of $\mathrm{NADH}$ and $\mathrm{NADPH}$ [3]; the other reported the rapid destruction of hemoglobin [4].

Corona discharge has also been shown to oxidize a polyethylene surface and induce the graft polymerization of acrylamide [5], and to oxidize inorganic molecules. One report claimed that mixtures of $\mathrm{SE}_{6}$ and water subjected to point-to-plane $50 \mathrm{~Hz}$ ac corona discharges produced only stable gaseous by-products of $\mathrm{SOF}_{2}$ and $\mathrm{SO}_{2} \mathrm{~F}_{2}$ as detected by GC or GC-MS [6]. Another study reported the oxidation of copper, silver, and gold foils [7].

oxygen free radicals and related species have been shown to effectively destroy several organic hazardous spectes. A reaction process that breaks down industrial solvents, pesticides, dioxins, PCB's, and munitions chemicals into smaller, safer products has been demonstrated using titanium dioxide as a catalyst and the sun's ultraviolet light. In this process, hydroxyl radicals and peroxide ions are believed to break down the hazardous organics into water, carbon dioxide, and some very dilute acids [8]. Others have shown that a reaction involving the superoxide ion $\left(\mathrm{O}_{2}^{-}\right)$will. convert $\mathrm{PCB}$ 's into bicarbonate of soda and halide ions. This is accomplished via the in situ electrolytic reduction of dissolved oxygen [1]. The same authors suggested that $\mathrm{O}_{2}^{-}$ generated in solution can react with $\mathrm{PCB}^{\prime} \mathrm{s}$ to form $\mathrm{HCl}$ and carbonic acid.

Reaction rates, kinetics, and mechaniums of the effects from corona discharge have also been studied. $\mathrm{SO}_{x}$ and $\mathrm{NO}_{x}$ have been successfully removed from iron-ore sintering machine flue gas using high energy electrons in the presence of $\mathrm{NH}_{3}$. Oxidation by corona discharge creates ammonium sulfate and ammonium nitrate precipitates $[9,10]$. Similar tests have been run on synthetic coal-fired boller flue gases [10].

Sulfur dioxide has been converted to sulfuric acid mist by corona discharge. The rate-determining step was the formation of atomic oxygen by electrical discharge. The concentration of $\mathrm{SO}_{2}$ was $500-3000$ ppm in a flowing humid air mixture. Optimum reaction rates occurred at $70 \%$ relative humidity and above a $15 \%$ oxygen concentration [11]. $\mathrm{SO}_{2}$ removal was enhanced when the liquid surface was subjected to corona discharge, with the bulk of the acid deposition within the chamber. Gas-phase oxidation of $\mathrm{SO}_{2}$ in the absence of water was minimal [12].

A negatively charged electrode placed in the gas phase above grounded water will generate superoxide $\left(\mathrm{O}_{2}^{-}\right)$[13] and ozone $\left(\mathrm{O}_{3}\right)$ [8]. In the presence of tron salts, superoxide can also be converted to hydrogen peroxide and the highly reactive hydroxyl radical [14]. Reports indicate that ion species created by corona discharge in air at atmospheric pressure also include $\mathrm{CO}_{3}^{-}, \mathrm{CO}_{3}^{-}\left(\mathrm{H}_{2} \mathrm{O}\right) \times,(\mathrm{x}=1,2), \mathrm{O}^{-}, \mathrm{NO}_{2}^{-}, \mathrm{O}_{3}$, $\mathrm{O}_{3}, \mathrm{NO}^{+}, \mathrm{NO}_{2}{ }^{+}, \mathrm{N}_{2}$ and $\mathrm{H}^{+}\left(\mathrm{H}_{2} \mathrm{O}\right)_{\mathrm{n}}(\mathrm{n} \leq 9)$ [1.5-17]. These ions and radicals are highly unstable and may react with a broad 
spectrum of organics. The present report demonstrates the ability of corona discharge to bleach varlous organic dyes. These reactions may become useful as indicators of coronastimulated reactions.

\section{MATERIALS}

A high voltage power supply (Kilovolt Corporation, Hackensack, NJ) was used with an output of up to ca. $15 \mathrm{kV}$. A dual-pen strip chart recorder (Soltec, San Fernando, CA), a PC600 colorimeter (Brinkman Instruments, Cleveland, $O H$ ) for constant on-line monitoring, and a picoammeter (Keithley Instruments, Cleveland, $\mathrm{OH})$ were also used to record the current between the two electrodes. Initial spectrophotometric results were obtained using a Varian DMS200 UV-Vis spectrophotometer (Varian Instruments, Sunnyvale, california). The reaction chamber consisted of a one liter wide mouth flask with 6 access ports (Figure 1). The ports were fitted with ground glass stoppers. Each port had access-tube options such that electrodes or gasses could be introduced near the bottom, middle, or top of the reaction chamber (Figure 1). A stainless steel anode with a sharpened point was placed above the water level, inserted through one of the six ports of the reaction vessel. The platinum cathode (ground) was insulated through the gas phase of the chamber by a glass tube, but exposed at the bottom of the vessel. It was inserted into the vessel through another port at the top. The electrodes were insulated using glass tubes which were connected by ground glass joints to help seal the vessel from external air. The cathode was inserted through a glass tube which protruded into the liquid phase all the way to within about 1/4" of the bottom of the flask. The anode was connected to the power supply and served as the ion source. Efforts have been made to minimize the number of construction materials present in the reaction chamber. The main substance with which material came into contact was glass, which appeared to have been resistant to degradation. Teflon stirrer bars were used. The stainless steel electrodes appeared to corrode in the reaction vessel, while the platinum (grounded) electrode did not.

Reagents used were methylene blue (Kodak, Rochester, NY), Malachite Green (Sigma Chemical, St. Louls, MO), New Coccine (Aldrich Chemical, Milwaukee, WI), and silicic acid (Mallinckrodt, Paris, KY). Water was purified using a Milli. $Q$ water purification system (Mililpore Corp., Bedford, MA). 


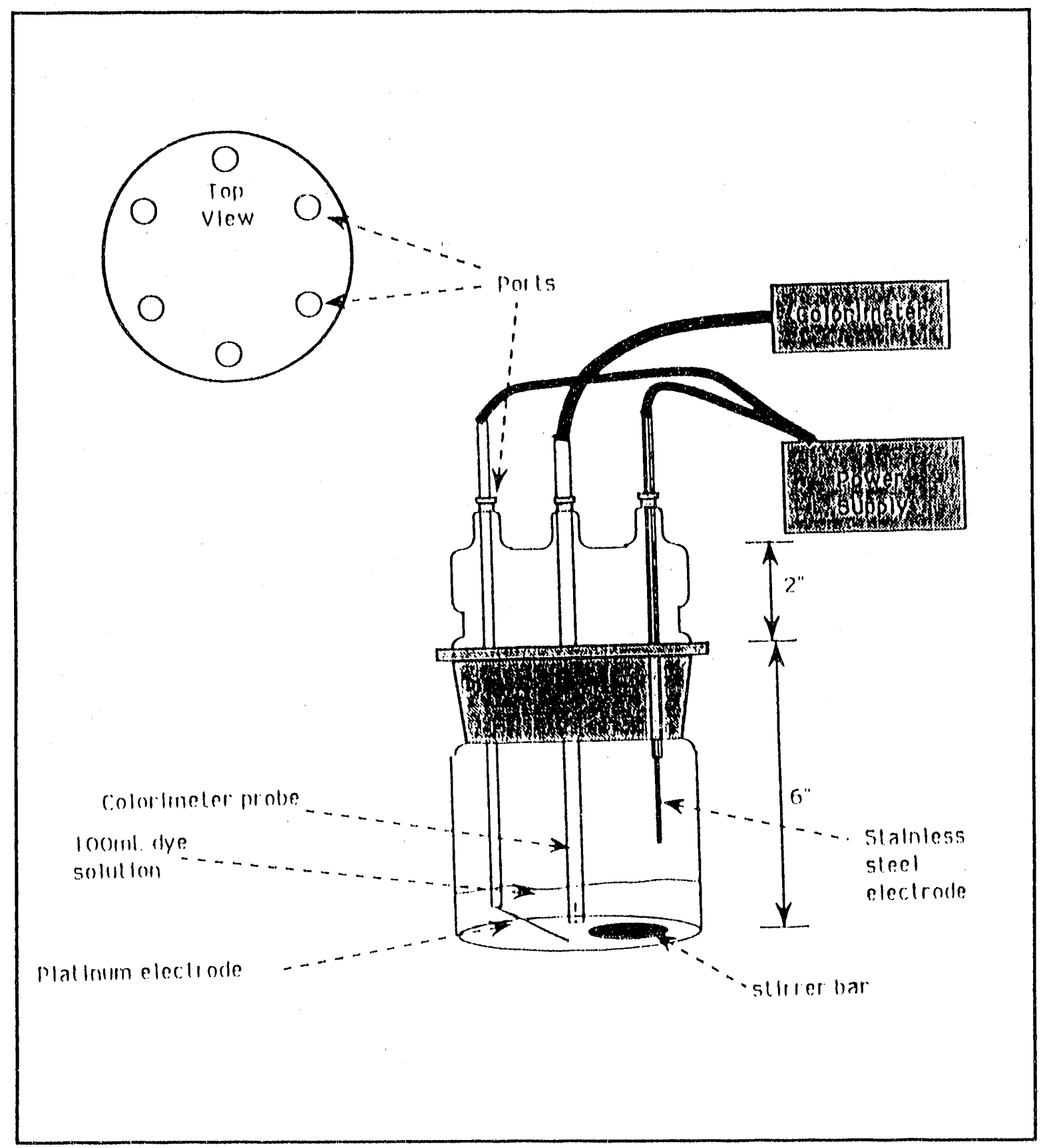

Figure 1. Reaction Vessel.

A glass two liter reaction vessel was used for all experiments. $100 \mathrm{ml}$ of dye in Milli-Q deionized water was placed in each vessel. A dc power supply provided up to $15 \mathrm{kV}$ between the electrodes, with the negatively charged corona above the water surface. A tefion magnetic stirrer bar was used with continuous, vigorous stirring in all cases. The vessel was kept sealed during most experiments. 


\section{METHODS}

A concentration of $6 \mu \mathrm{g} / \mathrm{mL}$ of dye in water was used in all cases. This concentration was chosen because it was found to show best results without overloading the sensitivity of the detector. Absorbance was measured continuously using a submersible fiber optic cell, supplied with the PC600 colorimeter. Current between the two electrodes (stainless steel and platinum) was measured continuously, using a picoammeter. Typicaliy, 5 - 15,000 Volts were used which resulted in a current of $\mathrm{Ca} .10$ to $50 \mu \mathrm{A}$. Current fluctuations of $\mathrm{Ca} .10 \%$ were often present, largely due to rigorous stirring. When the magnetic stirrer bar was removed, or the stirrer was turned off, current fluctuated only slightly. All experiments were carried out with one control. Controls consisted of aliquots of mixed solutions of dye which were stirred adjacent to the exposed fractions, but without current between the electrodes.

\section{RESULTS}

Several experiments were carried out exposing methylene blue, malachite green, and other dyes to corona discharge in the presence of air, using the reaction vessel shown in Figure 1. All dyes were dissolved in water as described in Methods. In the presence of air and at ambient temperature, methylene blue lost most of its color (absorbance) within four hours of exposure to $10 \mathrm{kV}$ and $20 \mu \mathrm{A}$ or corona discharge. Figure 2 shows the change in absorbance of a $6.0 \mu \mathrm{g} / \mathrm{mL}$, solution of methylene blue at $664 \mathrm{~nm}$ both with and without (control) exposure to corona discharge. Approximately half of that absorbance was lost within one hour under these conditions. There was little or no change in absorbance aftel 4.5 hours of exposure to corona discharge. The experiment was ended after 24 hours.

Malachite green (Figure 3) and new coccine (Eigure 4) behaved in a similar manner in the presence of corona discharge and under the same conditions.

Experiments were also performed under different atmospheric conditions (in the presence of $\mathrm{N}_{2}, \mathrm{O}_{2}, \mathrm{He}$, individualiy) to determine their effect on reaction rates. Results from these experiments indicated dyes reacted rapidly only in the presence of oxygen and corona discharge to form colorless solutions (Figures 2-4). For these and in subsequent experiments, methylene blue was chosen rather than all three dyes.

Experiments were performed to measure the effect of current on bleaching rate of methylene blue (Figure 5). Current was adjusted by changing the voltage. Reaction rates were measured as a function of current by following the loss of color. The reaction rate increased with increasing 


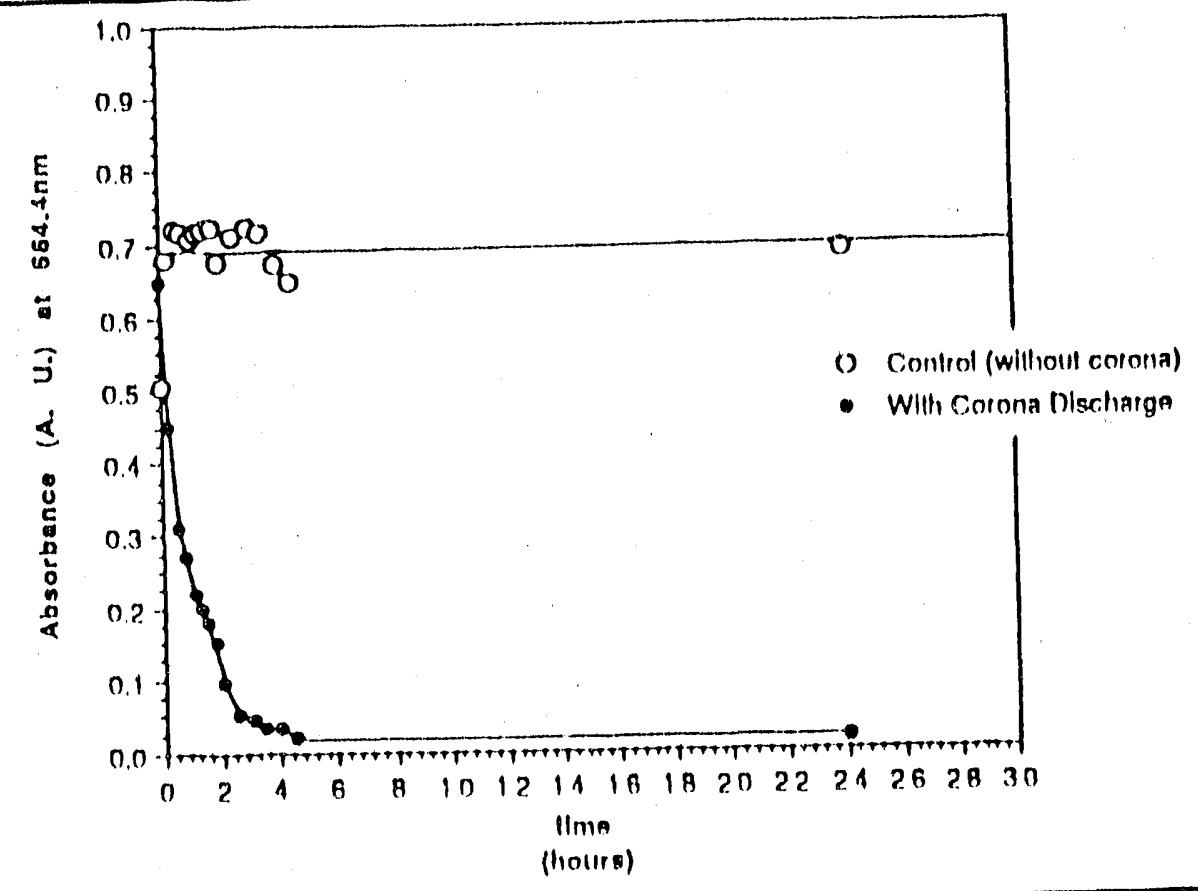

Figur 2. Methylene Blue at 664.4 nin.

The change in absorbance at $664 \mathrm{~nm}$ of a $100 \mathrm{mg} / \mathrm{mL}$ solution of methylene blue with and wlthout exposure to corona discharge is shown. The exposure chamber used for these experiments is shown in Figure 1. A $10 \mathrm{kV}$ potential and $20 \mu \mathrm{A}$ current were used for the corona exposed solution. More than half the absorbance was lost in the first hour of exposure. Little additional change in absorbance occurred between 4.5 and 24 hours of exposure to corona discharge. No significant effects were observed in the absence of corona discharge.

current. The rate of this increase was proportional to the current.
There was little or no reaction in the presence of helium, a substantial reaction (faster than air) in the presence of oxygen, and no reaction in the presence of nitrogen 5). The current between the electrodes (at 10 kV do power supplied) fluctuated wildly in the presence of helium, was constant in the presence of oxygen, as well as in the presence of nitrogen, the current was ca. $150 \mu \mathrm{A}$, significantly higher than in air, at a constant voltage of $5 \mathrm{kV}$. Fluctuations in current coincided with the motion of the aqueous solution during stirring. An experiment with $0.15 \mathrm{M} \mathrm{NaCl}$ in the methylene blue solution indicated that $\mathrm{NaCl}$ substantially slowed the bleaching reaction (Eigure 5).

In the flasks in which solutions were exposed to corona, water directly under the electrode was disturbed, even in the absence of mechanical stirring. The disturbance appeared like a dimple, similar to the effect of blowing a small 


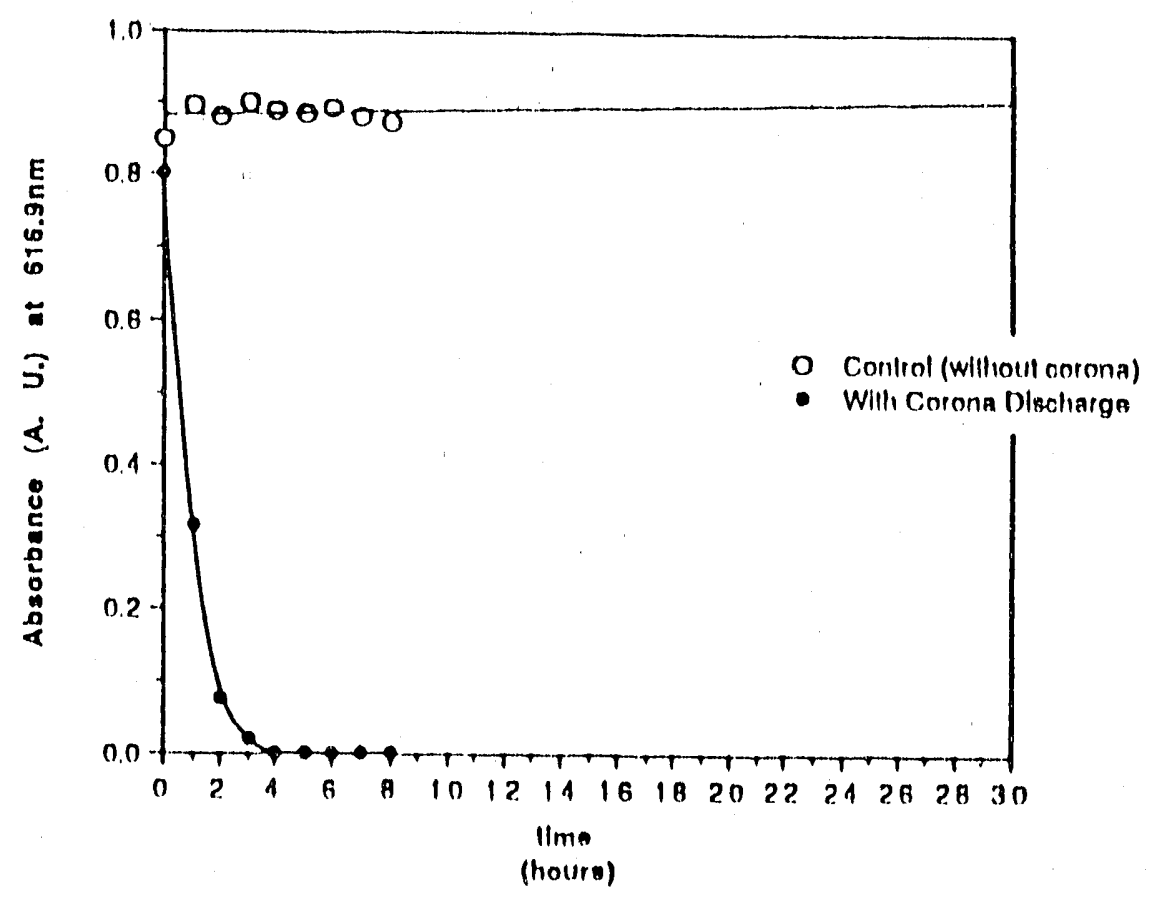

Figure 3. Malachite Green at $616.9 \mathrm{~nm}$.

The change in absorbance at $616.9 \mathrm{~nm}$ of a $100 \mathrm{mg} / \mathrm{mL}$ solution of malachite green with and without exposure to corona discharge is shown. A $10 \mathrm{kV}$ potential and $20 \mu \mathrm{A}$ current were used for the corona exposed solution. More than half the absorbance was lost in the first hour of exposure. Little additional change in absorbance occurred letween 4.5 and 24 hours of exposure to corona discharge. No significant effects were observed in the absence of corona djscharge.

stream of air directly down on the water surface. We referred to this effect as the "corona wind".

\section{DISCUSSION AND CONCIUUSION}

Many efforts have been made to explore the efficiency of corona emitters. For example, it has been shown that a triangle-shaped point-to-plane geometry electrostatic dc corona device is more efficient than a point-to-plane dc corona device with a rectangular cross section [18]. A semiempirical mathematical model was used to describe the electrical characteristics and to refine estimates on the optimum shape of the device [18]. Experiments have also shown that a greater voltage was required to generate corona discharges when the anode radius was increased [19].

Furthermore, when cylindrical hollow electrodes generate corona discharge, the temperature of the electrodes has been shown to increase [20]. In the present study, the point-to- 


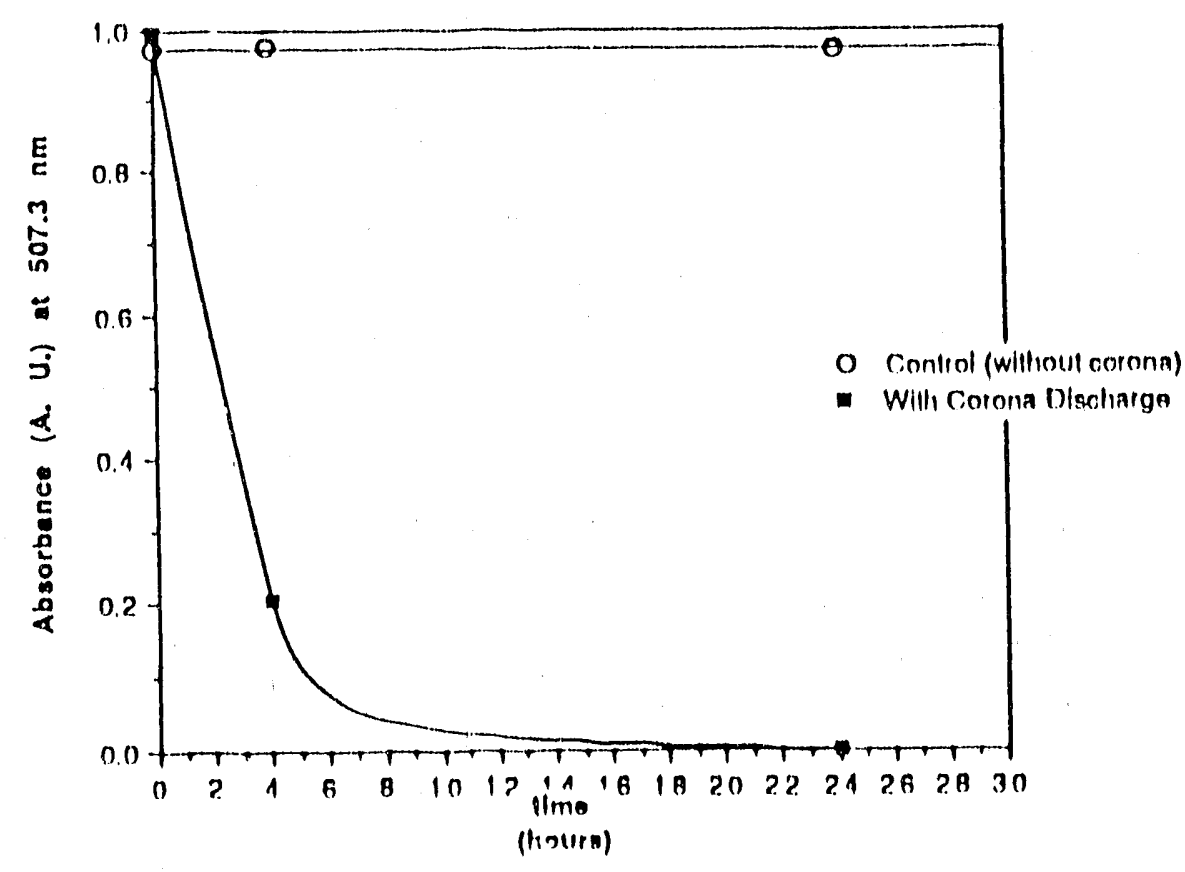

Figure 4. New Coccine at $507.3 \mathrm{~nm}$.

The change in absorbance at $507.3 \mathrm{~nm}$ of a $1.00 \mathrm{mg} / \mathrm{mL}$ solution of new coccine with and without exposure to corona discharge is shown. A $10 \mathrm{kV}$ potential and $20 \mu \mathrm{A}$ current were used for the corona exposed solution. More than half the absorbance was lost in the first hour of exposure. Little additional change in absorbance occurred between 4.5 and 24 hours of exposure to corona dissharge. No significant effects were observed in the absence of corona discharge.

plane geometry was chosen with the aqueous surface acting as the (grounded) plane. The pointed electrode was solid, not hollow, and composed of stainless steel.

In the presence of gases other than air, the current, but not the reaction rate, was greater in the presence of nitrogen. Corona discharges have previously been shown lu be enhanced in a nitrogen atmosphere [21]. However, the present study demonstrates that current and composition of gas phase both influence the rate of the reaction, and that oxygen is involved.

Frevious attempts have been made to develop reactions using electrical oxidation of gas pollutants. One of these was an electrochemical flow reactor (essentially an electrostatic precipitator with a catalyst) developed to oxidize a large volume of gas with hydrocarbon pollutants. However, the reactor apparently precipitated the hydrocarbons to the inner wall (outer electrode) of the reactor in the presence of corona discharge [22]. In the present study, no 


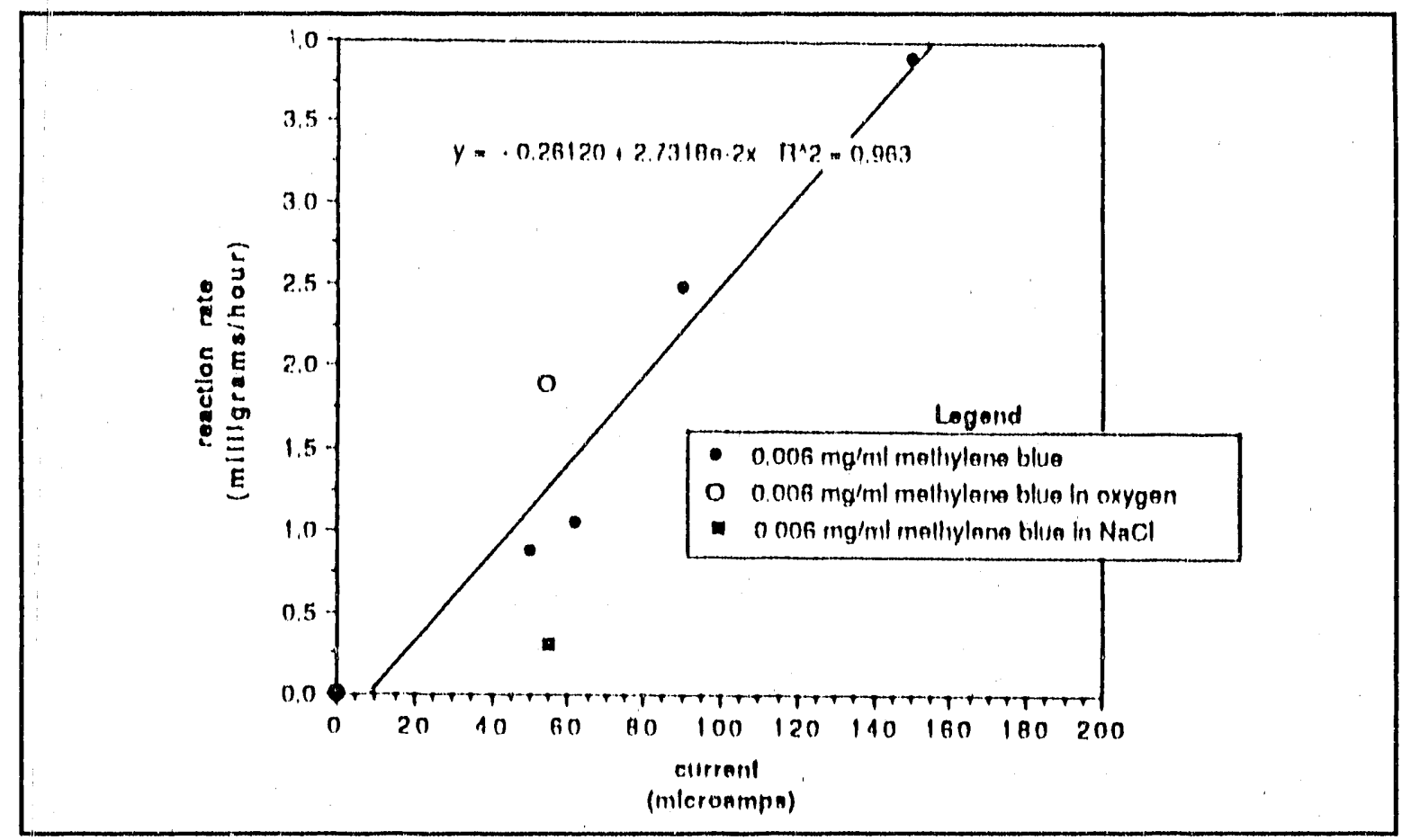

Figure 5. Effect of Current on Reaction Rate.

Figure 5 shows the initial reaction rate of methylene blue when exposed to corona discharge versus current (between the two electrodes of Figure 1). Condttions were the same as for Figure 2. The dark circles were from experiments in ambient atr, using only water as the solvent. The open circle represents the reaction rate in the presence of oxygen. The dark square represents the reaction rate when $0.15 \mathrm{NaCl}$ was used in the solvent.

precipitates or dye deposits were observed in the reaction vessel after bleaching had taken place.

Corona discharge is known to be responsible for the generation of superoxide [13], singlet oxygen [3], and ozone [8] In the presence of water. The observed loss of dye absorbance may have been due to the destruction of dyes by any of a number of mechanisms. However, when hemoglobin was exposed to corona discharge in a similar system, ozone was suspected as the prime oxidizing component [4]. In the present studies, ozone or other species such as free radicals of oxygen and hydroxyl radical $(\mathrm{OH}-)$ could have been responsible for the observed reaction.

The reactions observed in this study were remarkable in that after the reaction was complete, no absorbarice remained within the absorbance range 200 to $900 \mathrm{~nm}$. This is similar to the effect observed previously for hemoglobin [4]. In that case, reaction products appeared to have been much lower in molecular welght than hemoglobin. Reaction products were not identified in either this or the earlier study. 
These experiments were undertaken to explore methods for optimizing degradation reactions in the presence of corona discharge. The advantage of using dyes is that the reactions could be monitored continuously by colorimetry. Effects were observed when NaCl. was added to the solvent, as well as when the gas phase was displaced with oxygen, helium, and nttrogen. In addition, we observed the reactions to be highly dependent upon stirring rate. The influence of current on the reaction rate (Figure 5) was possibly influenced by the composition of he ambient air. While no reaction took place in a nitrogen atmosphere, the current was very high. Oxygen reduced the current, but Increased the reaction rate. No reaction took place in the presence of hellum, but in that case current was also low. Voltage alone was poorly correlated with the reaction rate although higher. currents generally gave faster bleaching. Furthermore, the electrode spacing to the water surface greatly influenced current at the same voltage. This effect was most remarkable with rigorous stirring, causing current to fluctuate with the motion of the water surface. Attempts were made to control. the spacing, but under vigorous stiring conditions, current still. fluctuated. An average current was used for the data presented here. An explanation for poor correlations between current and voltage could have been poor control of the gas phase consumption. Small changes in humidity, temperatures, and particulates, as well as the geometry of the electrode tip may have influenced current at a fixed voltage. These variables are currently under investigation.

When oxygen was continuously blown into the reaction vessel, the bleaching of methylene blue proceeded more slowly than when there was no replenishment of oxygen. This suggests that species generated from oxygen, not oxygen alone, were responsible for the reaction. Lower flow rates of oxygen gave faster reactions. When we added oxygen near the end of a reaction, the rate was again dimintshed. This suggests that the reactions either required relatively small amounts of oxygen or adding fresh oxygen displaced the reaction species.

Reactions between species generated by corona discharge and the organic dyes used in this study were increased by increasing current, adding oxygen, and vigorous stirring. The reaction with methylene blue was also decreased by adding NaCl. These condtions may also enhance reactions with hazardous organic species in the presence of corona discharge. No reaction was observed when the vessel was filled with nitrogen, although current, corona glow, and the corona wind were enhanced. The diminished reaction in the presence of $\mathrm{NaCl}$ may have been due to the ability of $\mathrm{Na}^{+}$to either scavenge superoxide anions, or $\mathrm{NaCl}$ to protect the dye by coating the dye molecular surface. oxygen is clearly required for the dye to react with species generated by corona discharge. This supports the concept that either. free radicals of oxygen or ozone are involved in the dye bleaching reaction. 


\section{ACKNOWLEDGENTS}

The authors thank Richard Richardson for his assistance in designing the circultry for this project, and the $U . S$. Department of Energy for funding this research.

\section{RETERENCES}

1. Sugimoto, H., S. Matsumoto, D. T. Sawyer, 1988. "Degradation and Dehalogenation of Polychlorobiphenyls and Halogenated Aromatic Molecules by Superoxtde Ion and by Electrolytic Reduction." Envirenmental Science and Technelegy, $22(10): 1182-1186$.

2. Hoenig, S. A., G. T. Sill, L. M. Kelley, and K. J. Garvey, 1980. "Destruction of Bacteria and Toxic Organic Chemicals by a Corona Discharge." Air Pollution Control Association Journat, $30(3): 277-278$.

3. Bissel1, M. G., S. C. Goheen, E. C. Larkin and G. A. Rao, 1983. "Oxidation of Reduced Nicotinamide Adenine Dinucleotide by Negative Air Ions." Blechem. Archives, $1: 231-238$.

4. Goheen, S. C., M. G. Bissell, G. A. Rao and E. C. Larkin, 1.985. "Destruction of Human Hemoglobin in the presence of Water and Negative Alr. Ions Generated by Corona Discharge." Int.1.J. Biometerol., 29:353-359.

5. Iwata, H., A. Kishida, M. Suzuki, Y. Hata, and Y. Ikada, 1988. "Oxidation of Polyethylene Surface by Corona Discharge and the Subsequent Graft Polymerization." Journal of Polymer Science, Part A, 26(12):3309-3322.

6. Derdouri, A., J. Casanovas, R. Hergl1, R, Grob, and J. Mathieu, 1989. "Study of the Decomposition of wet SF6, Subjected to $50 \mathrm{~Hz}$ AC Corona Discharges." Jeurnal of Applied Physics,. 65(5):1852-1857.

7. Bigelow. R. W., 1988. "An xPS Study of Air Corona Discharge-Induced Corrosion products at $\mathrm{Cu}, \mathrm{Ag}$, and $\mathrm{Au}$ Ground Planes." Applied Surface Science, 32(1-2):122-140.

8. Goheen, S. C., E. C. Larkin and M. G. Bisse11, 1984. "Ozone Produced by Corona Discharge in the Presence of water." Intl. J.Biometerol.er 28:157-162.

9. Kawamura K. and V. H. Shui, 1984. "Pilot Plant Experience in Electron-Beam Treatment of Iron-ore Sintering Flue Gas and Its Application to Coal Boiler Flue Gas Cleanup." Physical Chemistry, 24(1):117-127. 
10. Clements, J. S., A. Mizuno, W. C. Finney, and R. H. Davis, 1989. "Combined Removal of $\mathrm{SO}_{2}, \mathrm{NO}_{\mathrm{X}}$, and $\mathrm{Fly}$ Ash fxom Simulated Flue Gas Using Pulsed Streamer Corona." IEEE Iransactions on Industry Applications, 25(1):62-69.

11. Matteson, M. J., H. L. Stringer, and W. L. Busbee. 1972. "Corona Discharge Oxidation of Sulfur Dioxide." Envirenmental Science \& Technology 6(10):895-901.

12. Vasishtha, N. and A. V. Someshwar, 1988. "Absorption Characteristics of sulfur Dioxide in water in the presence of a Corona Discharge." Industrial and Engineering Chemical Research, 27(7):1235-1241.

13. Kellogg, E. W., M. G. Yost, N. Barthakur and A. P. Kreuger, 197s. "Superoxide Involvement in the Bactericidal. Effects of Negative Air Ions on Staphylococcus albus." Nature, 281:400-401.

14. Halliwell, B., 1981. "The Bjological Effects of the superoxide Radical and its Products," in: clinical Resperatory Physiology, J. Hakin and M. Torres, ed., Pergamon Press:Oxford, pp. 21-28.

15. Williams, E. M., 1984. The Physics and Technelogy of Xeregraphic Processes, New York:Wiley-Interscience.

16. Shahin, M. M., 1969. "Nature of Charge Carriers in Negative Coronas." Appl. Opt. Suppl., 3:106-110.

17. Shahin, M. M., 1971. "Characteristics of corona Discharge and Their Application to Electrophotography." Phot. Sci. Eng., 15:322-328.

18. Yamamoto, T., P. A. Lawless, L. E. Sparks, 1989. "Triangle-shaped DC Corona Discharge Device for Molecular Decomposition." IEEE Transactiens on Industrial Applications, $25(4): 743-749$.

19. Nashimoto, K., 1988. "Silicon Oxide Projections Grown By Negative Corona Discharge." Japanese Journal of Applied physics,. $27(6): 892-898$.

20. Chang, J. S.and I. Maezono, 1988. "The Electrode Surface Temperature Profile in a Corona Discharge." Journal of Physics, D: Apol. Phys., $21(6): 1023-1024$.

21. Maezono, I. and J. S. Chang, 1988. "Flow-Enhanced Corona Discharge - The Corona Torch." Journal of Applied Physics, $64(6): 3322-3324$. 
22. Kipp, E., B. K. A. Shelstad, and G. S. P. Castle, 1973. "An Electrochemical Flow Reactor for Oxidation of Hydrocarbon pollutants." Canadian Journal of Chemical Engineering, $1(8): 494-498$. 


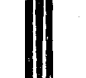

